\title{
Quantificação de depósitos do pulverizador tipo canhão em lavoura cafeeira com espaçamento convencional
}

\author{
Marcelo Augusto Bócoli* \\ Gustavo Rabelo Botrel Miranda** \\ Alessandra Rodrigues Carvalho *** \\ Alberto Donizeti Alves**
}

\section{Resumo}

Com o objetivo de quantificar os depósitos aplicados com pulverizador do tipo canhão, conduziu-se experimento no sul de Minas Gerais, em novembro de 2009, na lavoura de café cultivar Rubi, espaçamento de 3,80 x 0,80 m com altura média de 2,8 metros e 11 anos de idade. 0 experimento foi conduzido em DBC em esquema fatorial 2 x 2 com parcelas subdivididas no espaço, com 5 repetições. Foram estudados 2 fatores, volume de calda.ha ${ }^{-1}$ (300 e 600 L.ha $\left.^{-1}\right)$ e faixa de aplicação $(7,6$ e 15,2 metros). As parcelas constituíram-se das plantas de uma área de 16 metros por 15,2 metros (4 linhas de plantio), e as partes da planta (superior e inferior) foram consideradas subparcelas. Foi preparada uma solução marcadora composta pelo corante alimentício azul brilhante (FD\&C no 1) a 0,15\% (p/v), para que após a pulverização fossem coletadas 20 folhas de cada parcela, 10 na parte superior e 10 na parte inferior da planta. As folhas foram lavadas e a solução resultante foi lida em espectrofotômetro a $630 \mathrm{~nm}$. Transformou-se os valores de absorbância em ppm para formar a curva de concentração padrão. Os resultados foram submetidos a analise de variância (teste $\mathrm{F}$ ) e as médias comparadas pelo teste de Tukey, ao nível de 5\% de probabilidade, realizados com o software SISVAR 4.3. Concluiu-se que a aplicação das gotas é maior na parte superior do cafeeiro e que o volume de calda de 600 L.ha $^{-1}$ proporciona maior acúmulo de depósitos do que o volume de $300 \mathrm{~L}^{\mathrm{L}} \mathrm{ha}^{-1}$.

Palavras-chave: Faixa de aplicação. Volume de calda. Pulverizadores. Corante marcador. Tecnologia de aplicação.

\section{Introdução}

O modelo agrícola praticado no mundo depende de aplicar fitossanitários. A constante preocupação com os custos desses produtos e com o meio ambiente requer o uso de produtos seguros e eficientes e de técnicas de aplicação eficazes (Souza et al., 2007).

Existe um grande interesse na redução dos impactos ambientais proporcionados pela agricultura, bem como uma forte demanda de alternativas que conduzam a sua sustentabilidade. Nesse contexto, a tecnologia de aplicação de defensivos empregada atualmente é extremamente desperdiçadora e não é adequada ao novo paradigma proposto. Na tentativa de melhorar a eficiência de aplicação, vários pesquisadores têm procurado alternativas que aumentem a deposição de produto nos alvos e reduzam a contaminação ambiental (Chaim, 1999).

A ocorrência de pragas, doenças e plantas infestantes no agroecossistema em importantes culturas (soja, milho, trigo, arroz, algodão, café) têm causado perdas de produtividade maiores que $30 \%$ do potencial produtivo, na média mundial, mesmo com práticas de controle (European Crop Protection Association - ECPA, 1992). Equipes multidisciplinares de pesquisadores têm trabalhado para compreender os problemas fitossanitários e encontrar formas de minimizá-los (Matthews, 2000).

Uma das formas mais utilizadas para salvaguardar as culturas das pragas tem sido a aplicação de produtos fitossanitários, especialmente sob a forma de pulverização (Ferreira et al., 2007). 
No uso de produtos via foliar, através de pulverização, é importante sua boa distribuição na folhagem. Ocorre que, em regiões montanhosas e lavouras adensadas, essa boa distribuição somente pode ser feita com pulverizadores costais ou de mangueiras, o que inviabiliza a aplicação em grandes áreas (Matiello et al., 2005).

Em vista dessas dificuldades, as grandes propriedades muitas vezes utilizam canhões pneumáticos, também conhecidos como "canhões atomizadores". Os canhões passam por carreadores, que precisam estar bem distribuídos nas lavouras, aplicam a calda por cima da copa, em horas com temperaturas mais amenas e de pouco vento, principalmente à noite. A aplicação de um volume maior de calda (400-500 L.ha-1) tem obtido resultados aceitáveis para controle de bicho mineiro, correção de micronutrientes e controle de broca (Matiello et al., 2000).

Dependendo do tipo de operação, do equipamento disponível e da praga a ser controlada, é importante definir a faixa de aplicação, para assim obter melhor controle nos tratamentos (Teixeira, 1997).

Na maioria das vezes, dá-se muita importância ao produto fitossanitário a ser aplicado e pouca à técnica de aplicação. Contudo, não basta conhecer o produto a ser aplicado, também é fundamental conhecer a forma de aplicação (Cunha, 2003).

A eficiência de aplicação do pulverizador do tipo canhão na lavoura cafeeira é muito questionada, mas existem poucos trabalhos científicos atuais que sustentem tais questionamentos. Dessa forma, o presente trabalho se presta a analisar cientificamente a eficiência na quantificação de depósitos após pulverização com canhão.

Para isso, foi feita verificação e quantificação do volume de depósitos na lavoura cafeeira em espaçamento convencional pulverizada com pulverizador do tipo canhão, quantificando os depósitos de calda aplicada em diferentes partes da planta de café e verificando a melhor faixa de aplicação para a pulverização com pulverizador do tipo canhão em lavoura cafeeira com espaçamento convencional.

\section{Material e métodos}

O presente trabalho foi desenvolvido no Sul de Minas, em lavoura de café da cultivar Rubi, em plantio convencional, com 11 anos de idade, com espaçamento de 3,80 x 0,80 m, uma planta por cova, estando com altura média de 2,8 metros e localizando-se na latitude de $21^{\circ} 22^{\prime}$ e longitude de $46^{\circ} 31^{\prime}$ e 1020 metros de altitude. Foi utilizado pulverizador do tipo canhão de ar da marca Jacto, modelo AJ-401 LH PLUS, acoplado ao trator New Holland, modelo TT 3880 F com 75 cv (55 KW).

0 experimento foi conduzido em delineamento de blocos casualizados em esquema fatorial $2 \times 2$ com parcelas subdivididas no espaço e 5 repetições.

Os fatores estudados foram volume de calda (300 e 600 L. ha- $\left.{ }^{-1}\right)$ e faixa de aplicação $(7,6$ e 15,2 metros) (Tabela 1).

Tabela 1: Tratamentos e condições operacionais utilizadas na pulverização.

\begin{tabular}{ccccc}
\hline Tratamento & $\begin{array}{c}\text { Volume de Calda } \\
(\text { L.ha- })\end{array}$ & $\begin{array}{c}\text { Faixa de Aplicação } \\
(\mathbf{m})\end{array}$ & $\begin{array}{c}\text { Velocidade } \\
\left(\mathbf{k m} \cdot \mathbf{h}^{-1}\right)\end{array}$ & $\begin{array}{c}\text { Vazão } \\
\left(\text { L.min }^{-1}\right)\end{array}$ \\
\hline $\mathbf{1}$ & 300 & 7,6 & 2,95 & 11,21 \\
$\mathbf{2}$ & 300 & 15,2 & 2,00 & 15,20 \\
$\mathbf{3}$ & 600 & 7,6 & 2,00 & 15,20 \\
$\mathbf{4}$ & 600 & 15,2 & 2,00 & 30,40 \\
\hline
\end{tabular}

Fonte: elaboração própria.

As parcelas constituíram-se das plantas de uma área de 16 metros (20 plantas) por 15,2 metros (4 linhas de plantio úteis), e as partes da planta (superior e inferior) foram consideradas as subparcelas. 0 tratamento 1 e o tratamento 3 foram pulverizados com sobreposição, de modo que a pulverização foi realizada na primeira, na terceira e na quinta linha, e as folhas para análise foram coletadas na terceira, quarta, quinta e sexta linha de plantio, nas quais houve sobreposição de faixas de aplicação. 
Nos tratamentos 2 e 4 a pulverização foi realizada na primeira e na quinta linha, sem sobreposição. E a coleta foi realizada também na terceira, quarta, quinta e sexta linhas, de modo que ocorre uma situação estabilizada de deposição a partir da contagem da terceira rua para o meio da lavoura.

Para avaliar quantitativamente as pulverizações, foi preparada uma solução marcadora composta pelo corante alimentício azul brilhante (FD\&C no 1) a 0,15\% (p/v) (Palladini, 2000).

A pulverização foi realizada no período de 19 a 21 de novembro de 2009. Durante a pulverização foram coletados os dados meteorológicos com termo-higro-anemômetro digital da marca Homis, modelo 906, posicionado a dois metros de altura da superfície do solo, conforme adotado por Scudeler et al. (2004).

Após a pulverização foram coletadas 20 folhas de cada parcela, 10 na parte superior e 10 na parte inferior da planta (subparcelas), do lado de cima e debaixo da linha, externa e internamente ao dossel da planta em cada subparcela.

As folhas foram coletadas com auxílio de luvas cirúrgicas e pinça anatômica dissecção $12 \mathrm{~cm}$ da marca $\mathrm{ABC}$, e colocadas em sacos plásticos devidamente identificados. Os sacos plásticos foram lacrados e acondicionados em caixa de isopor, que posteriormente foram levadas ao laboratório.

A cada amostra adicionou-se $100 \mathrm{ml}$ de água destilada, mantendo-a por agitação por cerca de 30 segundos para remoção do traçador. A solução resultante foi colocada em recipientes de vidro e mantida sob refrigeração. Após esse procedimento, os depósitos foram quantificados por um espectrofotômetro da marca FEMTO, modelo 700S, pela leitura de absorbância no comprimento de onda de $630 \mathrm{~nm}$.

Os valores de absorbância lidos pelo espectrofotômetro proporcionaram a sua transformação em ppm (mg. $\mathrm{L}^{-1}$ ) de acordo com a equação da curva-padrão estabelecida pelas diluições das amostras $(1 / 100,1 / 200,1 / 500,1 / 1000,1 / 2000,1 / 5000,1 / 10000)$ de cada calda de pulverização coletada no campo.

Como a concentração de calda foi a mesma em todos os volumes, verificou-se a mesma equação ( $y=0,0682 \mathrm{e}^{0,7728 x}$ ) para todos os tratamentos independente do valor de leitura da absorbância de cada volume, obtendo o valor da concentração em ppm do corante azul brilhante a partir da substituição do valor $\mathrm{x}$ da equação pelo valor da leitura da absorbância da amostra aferida no espectrofotômetro.

Após a remoção do corante marcador, mediu-se a área das folhas nas amostras onde se obteve a área foliar em centímetro quadrado $\left(\mathrm{cm}^{2}\right)$ a fim de calcular o volume líquido atingido na folha.

Para se calcular a área foliar, foram medidos comprimento e largura da folha a partir da fórmula proposta por Huerta (1962):

$$
A_{F}=C \cdot L \cdot 0,6666
$$

Em que:

$\mathrm{A}_{\mathrm{F}}=$ Área foliar em centímetro quadrado $\left(\mathrm{cm}^{2}\right)$;

$\mathrm{C}=$ Comprimento da folha em centímetro $(\mathrm{cm})$;

$\mathrm{L}=$ Maior largura da folha $(\mathrm{cm})$;

$0,6666=$ Constante.

Em seguida, determinou-se o volume depositado nas folhas através da seguinte equação:

$$
C i \cdot V i=C f \cdot V f
$$

Em que:

$\mathrm{Ci}=$ Concentração inicial da calda (1500 ppm);

$\mathrm{Vi}=$ Volume inicial a ser calculado;

$\mathrm{Cf}=$ Concentração final que corresponde à concentração encontrada na leitura do espectrofotômetro; $\mathrm{Vf}=$ Volume utilizado para lavar as folhas.

Após determinar o volume depositado, calculou-se a deposição em nanolitros (nL) de calda por centímetro quadrado $\left(\mathrm{cm}^{2}\right)$ de superfície foliar. 
Os resultados obtidos foram submetidos a uma analise de variância pelo teste $\mathrm{F}$ e as médias comparadas pelo teste de Tukey ao nível de $5 \%$ de probabilidade realizado pelo software de análises estatísticas SISVAR 4.3 (Ferreira, 2000).

\section{Resultados e discussão}

Os valores de temperatura, umidade relativa do ar e velocidade do vento registrados no momento das pulverizações com solução marcadora estão apresentados na tabela 2.

Tabela 2: Dados meteorológicos registrados no momento das pulverizações.

\begin{tabular}{cccc}
\hline Data & Temperatura $\left({ }^{\circ} \mathbf{C}\right)$ & $\begin{array}{c}\text { Umidade Relativa } \\
\text { do } \operatorname{ar}(\%)\end{array}$ & $\begin{array}{c}\text { Velocidade do vento } \\
\left(\mathbf{m . s}^{-1}\right)\end{array}$ \\
\hline $19 / 11 / 2009$ & 32,7 a 33,7 & 48,1 a 51,6 & 0,5 a 0,6 \\
$20 / 11 / 2009$ & 33,5 a 35,1 & 45,0 a 52,6 & 0,5 a 1,8 \\
$21 / 11 / 2009$ & 32,3 a 33,0 & 52,2 a 54,1 & 0,4 a 1,7 \\
\hline
\end{tabular}

Fonte: elaboração própria.

A quantificação do corante marcador possibilitou o estabelecimento da seguinte equação, com coeficiente de determinação $\mathrm{R}^{2}=0,9987$ para todos os volumes de calda:

$y=0,0682 \mathrm{e}^{0,7728 x}$

Em que:

$\mathrm{X}=$ leitura da densidade óptica (absorbância);

$\mathrm{e}=$ exponencial;

$\mathrm{Y}=$ concentração em ppm, pois a concentração de corante foi igual em todos tratamentos (Figura 1).

Figura 1. Curva de leitura de absorbância para inferir a concentração das amostras de calda de 300 e 600 L.haํ.1.

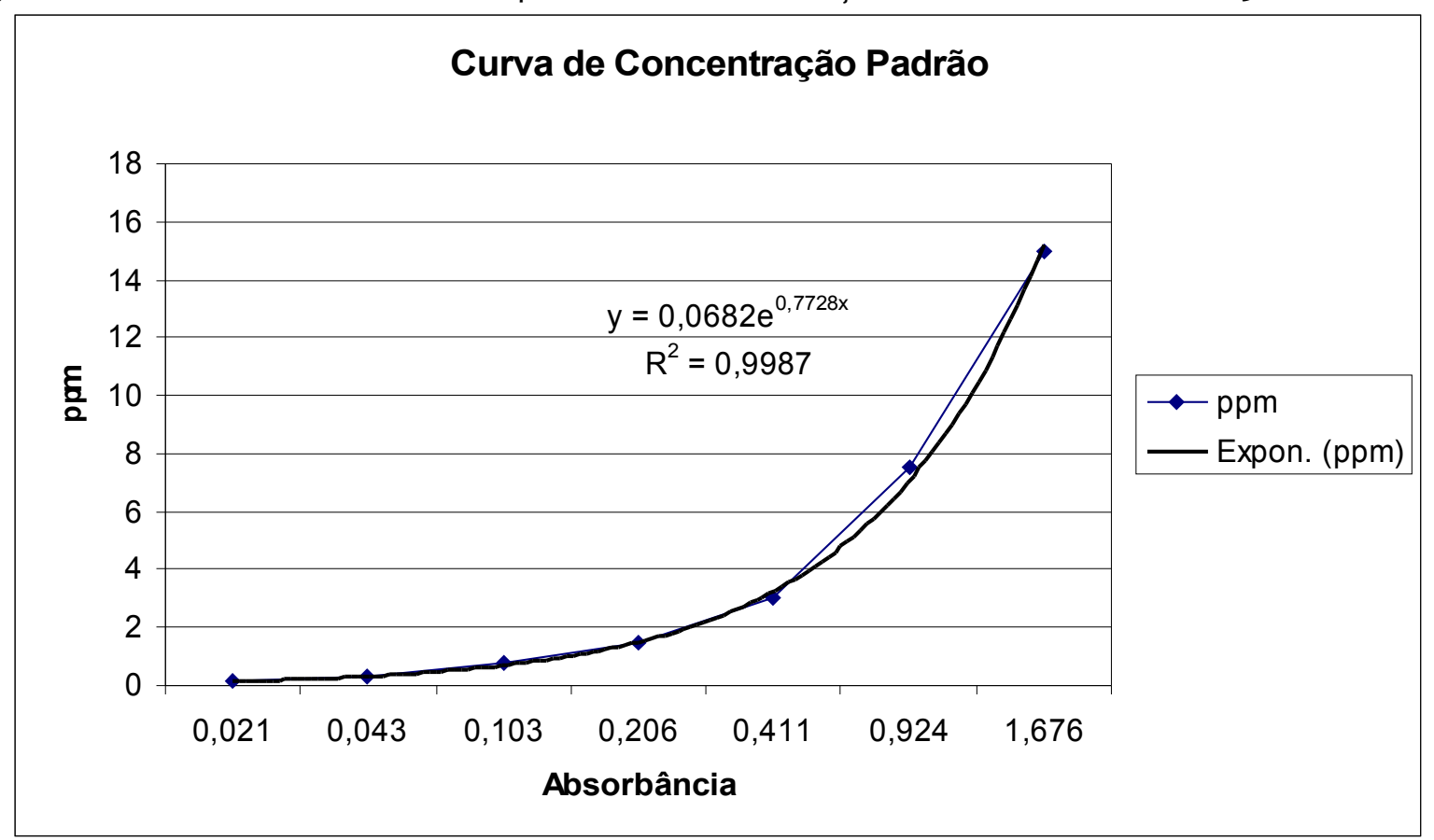

Fonte: elaboração própria. 
Pelo valor do coeficiente de determinação $\mathrm{R}^{2}$, verifica-se que a equação explica com precisão os valores de absorbância lidos no espectrofotômetro em função da alteração de concentração.

Verifica-se que os valores médios de depósitos não diferem significativamente entre as faixas de aplicação de 7,6 e 15,2 m para nenhum volume de calda aplicado, mas diferem entre os volumes de calda de 300 e 600 L.ha $^{-1}$, com valores superiores para o volume de 600 L.ha $^{-1}$ (Tabela 3).

Tabela 3: Valores médios de depósitos $\left(\mathrm{nL} . \mathrm{cm}^{-2}\right)$ após pulverização em diferentes faixas de aplicação e com diferentes volumes de calda.

\begin{tabular}{|c|c|c|c|c|}
\hline \multirow{3}{*}{$\begin{array}{l}\text { VOLUME DE } \\
\text { CALDA } \\
\left(\text { L.ha. }{ }^{-1}\right)\end{array}$} & \multicolumn{4}{|c|}{ Volume/Área Foliar (nL.cm $\left.{ }^{-2}\right)$} \\
\hline & \multicolumn{2}{|c|}{ FAIXA DE APLICAÇÃO (m) } & \multirow[b]{2}{*}{ Média } & \multirow[b]{2}{*}{ DMS } \\
\hline & 7,6 & 15,2 & & \\
\hline 300 & $18,40 \mathrm{~A}$ & $16,40 \mathrm{~A}$ & $17,40 \mathrm{~b}$ & 5,45 \\
\hline 600 & $22,30 \mathrm{~A}$ & $23,80 \mathrm{~A}$ & $23,05 \mathrm{a}$ & 5,45 \\
\hline Média & $20,35 \mathrm{~A}$ & $20,10 \mathrm{~A}$ & 20,22 & 10,0 \\
\hline $\mathrm{CV}(\%)_{\text {parcela }}$ & \multicolumn{4}{|c|}{27,68} \\
\hline $\mathrm{PR}>\mathrm{FC}_{\text {vol. calda }}$ & \multicolumn{4}{|c|}{0,0078} \\
\hline $\operatorname{Pr}>\mathrm{FC}_{\text {faix.apli./30oL }}$ & \multicolumn{4}{|c|}{0,4399} \\
\hline $\operatorname{Pr}>\mathrm{FC}_{\text {faix.apli. } / 600 \mathrm{~L}}$ & \multicolumn{4}{|c|}{0,5603} \\
\hline
\end{tabular}

Médias seguidas da mesma letra maiúscula na linha e minúscula na coluna não diferem entre si pelo teste de Tukey $\mathrm{p}<0,05$.

Fonte: elaboração própria.

O desdobramento da relação entre os fatores de estudo permitiu identificar a interferência do tratamento em relação à posição de amostragem (partes da planta).

A deposição nas diferentes partes da planta diferiu nos dois volumes de calda analisados, 300 e 600L.ha ${ }^{-1}$, com valores significativamente maiores para a parte superior da planta e com a utilização de 600 L.hä ${ }^{-1}$ (Tabela 4).

Tabela 4: Valores médios de depósitos $\left(\mathrm{nL} . \mathrm{cm}^{-2}\right)$ em diferentes partes da planta, após pulverização com diferentes volumes de calda.

\begin{tabular}{|c|c|c|c|c|}
\hline \multirow{3}{*}{$\begin{array}{c}\text { VOLUME DE } \\
\text { CALDA } \\
\left.\text { (L.ha. }{ }^{-1}\right)\end{array}$} & \multicolumn{4}{|c|}{ Volume/Área Foliar (nL.cm $\left.{ }^{-2}\right)$} \\
\hline & \multicolumn{2}{|c|}{ Partes da Planta } & \multirow[b]{2}{*}{ Média } & \multirow[b]{2}{*}{ DMS } \\
\hline & Superior & Inferior & & \\
\hline 300 & $21,50 \mathrm{~A}$ & $13,30 \mathrm{~B}$ & $17,40 \mathrm{~b}$ & 4,32 \\
\hline 600 & $29,00 \mathrm{~A}$ & $17,10 \mathrm{~B}$ & $23,05 \mathrm{a}$ & 4,32 \\
\hline Média & $25,25 \mathrm{~A}$ & $15,20 \mathrm{~B}$ & 20,22 & 20,0 \\
\hline CV (\%) parcela & \multicolumn{4}{|c|}{27,68} \\
\hline CV $(\%)_{\text {part. planta }}$ & \multicolumn{4}{|c|}{22,54} \\
\hline $\mathrm{PR}>\mathrm{FC}_{\text {vol. calda }}$ & \multicolumn{4}{|c|}{0,0078} \\
\hline $\operatorname{Pr}>\mathrm{FC}_{\text {part.planta/300 L. }}$ & \multicolumn{4}{|c|}{0,010} \\
\hline $\mathrm{Pr}>\mathrm{FC}$ part.planta/600 L. & \multicolumn{4}{|c|}{0,0000} \\
\hline
\end{tabular}

Médias seguidas da mesma letra maiúscula na linha e minúscula na coluna não diferem entre si pelo teste de Tukey a $\mathrm{p}<0,05$.

Fonte: elaboração própria.

Esse resultado contraria o de Miranda (2009), que, utilizando turbopulverizador hidráulico e com volumes de 300 e 600L. ha-1 ${ }^{-1}$ verificou maior deposição na parte inferior do cafeeiro, haja vista que o sentido da pulverização do turbo pulverizador é lateral enquanto que a do pulverizador do tipo canhão é sobre a copa do cafeeiro.

Scudeler et al. (2004) verificaram com uso de corantes traçadores que o volume de calda atingido na parte inferior do cafeeiro é maior que o volume de calda atingido na parte superior em pulverização com turbo pulverizador e pulverizadores costais. 
Essa divergência pode dever-se a três fatos. As gotas lançadas pelo pulverizador tipo canhão se depositam na planta de cima para baixo. A distância entre o turbo pulverizador e o alvo (planta) é menor quando comparada à distância entre o pulverizador tipo canhão e o alvo (planta). 0 formato trapezoidal do cafeeiro favorece a aproximação entre os ramos inferiores e o turbo pulverizador, e talvez isso facilite o acesso das gotas a essa parte da planta. Por outro lado, o formato trapezoidal pode dificultar a deposição no interior da planta quando utilizado o pulverizador tipo canhão.

Pode-se verificar também que, na pulverização com canhão, os níveis de depósitos são bem menores quando comparados com os verificados por Miranda (2009) e Scudeler et al. (2004) utilizando turbo pulverizador e pulverizadores costais.

As médias referentes ao desdobramento das partes da planta nas diferentes faixas de aplicação estão apresentadas na Tabela 5.

Tabela 5: Volumes médios de depósitos $\left(\mathrm{nL} . \mathrm{cm}^{-2}\right)$ em diferentes partes da planta após pulverização com diferentes faixas de aplicação.

\begin{tabular}{|c|c|c|c|c|}
\hline \multirow{3}{*}{$\begin{array}{l}\text { FAIXA DE APLICAÇÃO } \\
(\mathrm{m})\end{array}$} & \multicolumn{4}{|c|}{ Volume/Área Foliar (nL.cm $\left.{ }^{-2}\right)$} \\
\hline & \multicolumn{2}{|c|}{ Partes da Planta } & \multirow[b]{2}{*}{ Média } & \multirow[b]{2}{*}{ DMS } \\
\hline & Superior & Inferior & & \\
\hline 7,6 & $27,00 \mathrm{~A}$ & $13,70 \mathrm{~B}$ & $20,35 \mathrm{a}$ & 4,32 \\
\hline 15,2 & $23,50 \mathrm{~A}$ & $16,70 \mathrm{~B}$ & $20,10 \mathrm{a}$ & 4,32 \\
\hline Média & $25,25 \mathrm{~A}$ & $15,20 \mathrm{~B}$ & 20,22 & 10,0 \\
\hline CV (\%) parcela & \multicolumn{4}{|c|}{27,68} \\
\hline $\mathrm{CV}(\%)_{\text {part planta }}$ & \multicolumn{4}{|c|}{22,54} \\
\hline$P R>F C_{\text {faix. aplic }}$ & \multicolumn{4}{|c|}{0,8901} \\
\hline $\operatorname{Pr}>\mathrm{FC}_{\text {part.planta } / 7,6 \mathrm{~m}}$ & \multicolumn{4}{|c|}{0,0000} \\
\hline $\mathrm{Pr}>\mathrm{FC}_{\text {part.plant } / 15,2 \mathrm{~m}}$ & \multicolumn{4}{|c|}{0,0042} \\
\hline
\end{tabular}

Médias seguidas da mesma letra maiúscula na linha e minúscula na coluna não diferem entre si pelo teste de Tukey a $\mathrm{p}<0,05$.

Fonte: elaboração própria.

A deposição na parte superior da planta foi significativamente maior nas duas faixas de aplicação analisadas, mas sem diferença significativa entre as faixas de aplicação.

Atribuiu-se o fato de não haver diferença significativa entra as faixas de aplicação à baixa movimentação do ar no momento da pulverização.

Matuo (1983) afirma que, para conseguir uma deposição uniforme, é necessário sobrepor as faixas de aplicação, empregando faixas de aplicação que abranjam de 30 a $50 \%$ do alcance máximo da máquina, e que, em casos onde se empregam gotas muito pequenas, deve-se atentar para os fenômenos de evaporação e deriva, pois as gotas de água evaporam com facilidade e podem perder-se no espaço entre o bico e o alvo.

Espera-se também que com uma menor movimentação do ar, as gotas, que na pulverização com canhão se depositam de cima para baixo, tenham menor potencial de penetração no interior da planta e nas folhas presentes na parte inferior do cafeeiro.

Tal hipótese se confirmou em todos os resultados deste trabalho.

Para a interação volume de calda e faixa de aplicação com as partes da planta, verificou-se maior deposição na parte superior da planta em todos os volumes de calda e faixas de aplicação analisados (Tabela 6).

Estes resultados confirmam Matuo (1983) e Schroder (2009), que afirmam que a pulverização com pulverizador do tipo canhão apresenta deposição desuniforme.

Com relação à eficiência de defensivos aplicados com pulverizador do tipo canhão, Matiello et al. (2000) comprovaram que na aplicação de endossulfan (35\%) contra broca do café (Hypothenemus hampei F.), o resultado foi satisfatório, assim como na pulverização de micronutrientes em lavouras adensadas e em regiões montanhosas. Matiello et al. (2005) concluíram também que é viável o 
controle da ferrugem do cafeeiro (Hemileia vastratrix B.B.) via canhão com novas formulações de fungicidas (triazóis e estrubirulinas).

Matiello et al. (2005) também ressaltam que, na aplicação com canhão, deve-se ter cuidados especiais, aplicando em horas com temperaturas mais amenas e com pouco vento, principalmente à noite.

Como a deposição é maior na parte superior da planta, na aplicação com canhão é mais recomendável utilizar produtos sistêmicos com translocação basipetal. Dessa forma, pode-se abrir um novo nicho de mercado para formulações de defensivos, já que a grande maioria possui translocação acropetal, quando se trata de inseticidas e fungicidas.

Futuros trabalhos nessa linha de pesquisa poderão abordar aspectos como a interferência da velocidade de deslocamento do trator nos depósitos nas folhas de café (nesse caso, seria necessário maior estudo para comprovar essa interferência em velocidades menores). Outro ponto a ser estudado poderia ser o uso do canhão em lavouras com espaçamento convencional, ocasiões nas quais parte do produto aplicado pode se depositar nas entrelinhas da lavoura, podendo haver maior desperdício de produtos e maior contaminação ambiental, quando comparado ao turbo pulverizador.

Tabela 6: Volumes médios de depósitos $\left(\mathrm{nL} . \mathrm{cm}^{-2}\right)$ em diferentes partes da planta após pulverização com diferentes volumes de calda e diferentes faixas de aplicação.

\begin{tabular}{|c|c|c|c|c|c|}
\hline \multirow{3}{*}{$\begin{array}{l}\text { VOLUME DE } \\
\text { CALDA } \\
\text { (L.ha. }{ }^{-1} \text { ) }\end{array}$} & \multirow{3}{*}{$\begin{array}{c}\text { FAIXA DE } \\
\text { APLICAÇÃO } \\
(\mathrm{m})\end{array}$} & \multicolumn{4}{|c|}{ Volume/Área Foliar (nL. $\mathrm{cm}^{-2}$ ) } \\
\hline & & \multicolumn{2}{|c|}{ Partes da Planta } & \multirow[b]{2}{*}{ Média } & \multirow[b]{2}{*}{ DMS } \\
\hline & & Superior & Inferior & & \\
\hline \multirow[t]{2}{*}{300} & 7,6 & $23,20 \mathrm{~A}$ & $13,60 \mathrm{~B}$ & $18,40 \mathrm{a}$ & 6,11 \\
\hline & 15,2 & $19,80 \mathrm{~A}$ & $13,00 \mathrm{~B}$ & $16,40 \mathrm{a}$ & 6,11 \\
\hline \multirow[t]{2}{*}{600} & 7,6 & $30,80 \mathrm{~A}$ & $13,80 \mathrm{~B}$ & $22,30 \mathrm{a}$ & 6,11 \\
\hline & 15,2 & $27,20 \mathrm{~A}$ & $20,40 \mathrm{~B}$ & $23,80 \mathrm{a}$ & 6,11 \\
\hline \multicolumn{2}{|c|}{ Média } & $25,25 \mathrm{~A}$ & $15,20 \mathrm{~B}$ & 20,22 & 7,44 \\
\hline \multicolumn{2}{|c|}{$\mathrm{CV}(\%)_{\mathrm{parc}}$} & \multicolumn{4}{|c|}{27,68} \\
\hline \multicolumn{2}{|c|}{ CV (\%) subparc } & \multicolumn{4}{|c|}{22,54} \\
\hline \multicolumn{2}{|c|}{$\mathrm{Pr}>\mathrm{FC}_{\text {vol. calda }}$} & \multicolumn{4}{|c|}{0,0078} \\
\hline \multicolumn{2}{|c|}{$\operatorname{Pr}>\mathrm{FC}_{\text {faix. aplic }}$} & \multicolumn{4}{|c|}{0,8901} \\
\hline \multicolumn{2}{|c|}{$\operatorname{Pr}>\mathrm{FC}_{\text {part.planta } / 300 \mathrm{~L} \times 7,6 \mathrm{~m}}$} & \multicolumn{4}{|c|}{0,0042} \\
\hline \multicolumn{2}{|c|}{$\mathrm{Pr}>\mathrm{FC}$ part.planta/ $300 \mathrm{~L} \times 15,2 \mathrm{~m}$} & \multicolumn{4}{|c|}{0,0314} \\
\hline \multicolumn{2}{|c|}{$\mathrm{Pr}>\mathrm{FC}$ part.planta/ $600 \mathrm{~L} \times 7,6 \mathrm{~m}$} & \multicolumn{4}{|c|}{0,0000} \\
\hline \multicolumn{2}{|c|}{$\mathrm{Pr}>\mathrm{FC}_{\text {part.planta/ } 600 \mathrm{~L} \times 15,2 \mathrm{~m}}$} & \multicolumn{4}{|c|}{0,0314} \\
\hline
\end{tabular}

Médias seguidas da mesma letra maiúscula na linha e minúscula na coluna não diferem entre si pelo teste de Tukey a 5\% de significância.

Fonte: elaboração própria.

\section{Conclusões}

A maior quantidade de depósitos na pulverização com pulverizador do tipo canhão é encontrada na parte superior do cafeeiro.

O volume de calda de $600 \mathrm{~L} . h a^{-1}$ acumula maior quantidade de depósitos do que o volume de 300 L.ha-1.

Não há diferença de depósitos entre as faixas de aplicação de 7,6 e 15,2 m.

A viabilidade desse equipamento é mais justificável em lavouras adensadas ou em pulverizações de emergência para o cafeeiro. 


\section{Quantifying the deposits of the gun-type sprayer in cofee crop with conventional spacing}

\section{Abstract}

This study was carried out to quantify the deposits applied with the gun-type sprayer. So, an experiment was carried out on Southern Minas Gerais, on November 2009. The 11-yrs old coffee crop, cv. Rubi at 2.8 average height and spacing $3.80 \mathrm{X} 0.80 \mathrm{~m}$ was used. The experiment was conducted in DBC under factorial scheme $2 \times 2$ with plots subdivided in space, with five replicates. Two factors were studied: syrup volume.ha ${ }^{-1}$ (300 and 600L.ha ${ }^{-1}$ ) and application range (7.6 and $15.2 \mathrm{~m}$ ). The plots were composed by plants from an area of $16 \mathrm{~m}$ by $15.2 \mathrm{~m}$ ( 4 planting lines), whereas the plant parts (superior and inferior) were considered as subplots. It was prepared A marking solution composed by the feeding brilliant blue dye $\left(F D \& C n^{\circ} 1\right)$ at $0.15 \%(p / v)$ was prepared, so that 20 leaves from each plot were collected after pulverization, as being 10 at the superior and 10 at the inferior parts of the plant. The leaves were washed and the resulting solution was read in spectrophotometer at $630 \mathrm{~nm}$. The absorbance values were transformed into ppm to form the standard concentration curve. The results were subjected to variance analyzes ( $\mathrm{F}$ test) and the averages were compared by the Tukey test at $5 \%$ probability level, by using the software SISVAR 4.3. The application of the drops was concluded to be higher at the superior part of the coffee shrub and the syrup volume of 600L.ha-1 provides higher deposit accumulations than the volume of 300L.ha-1. Keywords: Application range. Syrup volume. Sprayers. Coloring marker. Application technology.

\footnotetext{
* Bacharel em Tecnologia em cafeicultura do Instituto Federal de Educação, Ciência e Tecnologia do Sul de Minas Gerais, campus Muzambinho.

** Professores do Instituto Federal de Educação, Ciência e Tecnologia do Sul de Minas Gerais, campus Muzambinho. E-mail: grbmiranda@gmail.com

*** Técnico administrativo do Instituto Federal de Educação, Ciência e Tecnologia do Sul de Minas Gerais, campus Muzambinho.
}

\section{Referências bibliográficas}

CHAIM, A. Pulverização eletrostática como alternativa para redução do uso de agrotóxicos. Jaguariúna, 1999. p.1. Disponível em: <http://www.agencia.cnptia.embrapa.br/.../Chaim_pulverizacaoID-2bQck4Ciug.pdf>. Acesso em: 19 out. 2009.

CUNHA, J.P.A.R. et al. Avaliação de estratégias para redução da deriva de agrotóxicos em pulverizações. Planta Daninha, Viçosa-MG, v.21, n.2, p.325-332, 2003. Disponível em: <http://www.scielo.br/pdf/pd/v21n2/a19v21n2.pdf>. Acesso em 15 out. 2009.

EUROPEAN CROP PROTECTION ASSOCIATION (ECPA). Cereals and plant protection. ECPA: Summary of the Cereal Chapters, $1992.16 \mathrm{p}$.

FERREIRA, D.R. Análises estatísticas por meio do Sisvar para Windows versão 4.0. In: REUNIÃO ANUAL DA REGIÃO BRASILEIRA DA SOCIEDADE INTERNACIONAL DE BIOMETRIA, 45., 2000, São Carlos. Anais... São Carlos: UFSCar, 2000. p.255-258.

FERREIRA, M.C. et al. Fatores qualitativos da ponta de energia hidráulica ADGA 110015 para pulverização agrícola. Eng. Agríc., Jaboticabal, v.27, n.2, p.471-478, maio/ago.2007. Disponível em: <http://www.scielo.br/pdf/eagri/v27n2/a16v27n2.pdf>. Acesso em: 10 set. 2009. 
HUERTA, S.A. Comparación de métodos de laboratorio y de campo para medir el área foliar del cafeto. Cenicafé, Caldas, v.13, n. 1, p.33-42, ene./mar. 1962.

MATIELLO, J.B.; BARROS, U.V.; BARBOSA, C.M. Controle da broca do café (H. hampei) em cafezal conillon com aplicações via canhão-atomizador. Anais do $26^{\circ}$ Congresso Brasileiro de Pesquisas Cafeeiras, CBPC. p.66. Marília, SP. 2000.

MATIELLO, J.B.; FREITAS J.L.; GOUVÊA, L. Fernando. Controle da ferrugem do cafeeiro via canhãoatomizador com formulações de triazóis e estrubirulinas. Revista Brasileira de Tecnologia Cafeeira - Coffea. Ano 2 - № 5 - Janeiro/Fevereiro - 2005.

MATTHEWS, G.A. Pesticide application methods. London: Longman, 2000. 448 p.

MATUO, T. Fitossanidade do Algodoeiro. Trabalhos Apresentados. In: Simpósio Hoechst - Rio de Janeiro, p 33 - 36. 25 e 26 de agosto de 1983.

MIRANDA, G.R.B. Distribuição de inseticidas em frutos de cafeeiro (Coffea arábica L.) e eficiência no controle da broca do cafeeiro (Hypothenemus hampei F.). 2009. 133f. Tese (Doutorado) - Universidade Estadual Paulista "Júlio de Mesquita Filho" Faculdade de Ciências Agronômicas Campus de Botucatu, 2009.

PALLADINI, L. A. Metodologia para avaliação da deposição em pulverizações. 2000. 111f. Tese (Doutorado em Agronomia/Proteção de Plantas) - Faculdade de Ciências Agronômicas, Universidade Estadual Paulista, Botucatu.

SCHRODER, E.P. Proteção com tecnologia. Disponível em:

<http://www.megabio.com.br/ambiente_2.html>. Acesso em 17 out. 2009.

SCUDELER, F. et al. Cobertura da pulverização e maturação de frutos do cafeeiro com ethephon em diferentes condições operacionais. Bragantia, Campinas, v.63, n. 1, p. 129-139, 2004. Disponível em: <http: www.scielo.br/pdf/brag/v63n1/a13v63n1.pdf>. Acesso em 14 out. 2009.

SOUZA, R.T.; VELINI, E.D.; PALLADINI, L.A. Aspectos metodológicos para análise de depósitos de pulverizações pela determinação de depósitos pontuais. Planta Daninha, Viçosa-MG, v. 25, n. 1, p. 195-202, 2007. Disponível em: <http://www.scielo.br/pdf/pd/v25n1/a22v25n1.pdf>. Acesso em: 15 nov. 2009.

TEIXEIRA, M.M. Influencia del volumen de caldo y de la uniformidad de distribución transversal sobre la eficacia de la pulverización hidraulica. 1997. 310 f. Tese (Doutorado em Engenharia Rural). Universidad Politécnica de Madrid, Madrid, 1997. 